American Journal of Applied Sciences 7 (2): 270-276, 2010

ISSN 1546-9239

(C) 2010 Science Publications

\title{
Improved Dielectric Model for Polyvinyl Alcohol-Water Hydrogel at Microwave Frequencies
}

\author{
${ }^{1}$ You Kok Yeow, ${ }^{2}$ Zulkifly Abbas, ${ }^{2}$ Kaida Khalid and ${ }^{3}$ Mohamad Zaki Abdul Rahman \\ ${ }^{1}$ Department of Radio Communication Engineering, Faculty of Electrical Engineering, \\ University Technology Malaysia, 81310 UTM Skudai, Malaysia \\ ${ }^{2}$ Department of Physics, \\ ${ }^{3}$ Department of Chemistry, \\ Faculty of Science, University Putra Malaysia, 43400 UPM Serdang, Malaysia
}

\begin{abstract}
Problem statement: The study described rigorous dielectric modeling for Polyvinyl Alcohol (PVA)-water hydrogel mixture at microwave frequencies. Approach: A commercial openended coaxial sensor was used to measure the dielectric constant, loss factor and ionic conductivity, $\sigma$ of PVA-water hydrogel mixture ranging concentration of $80-100 \%$ water content. Results: The sensor was operating between 0.13 and $20 \mathrm{GHz}$ at and above of room temperature $(25 \pm 1)^{\circ} \mathrm{C}$. Indirectly, the relaxation time, $\tau$, activation energy, $\mathrm{Q}$ and entropy change, $\Delta \mathrm{S}$ of the hydrogel mixtures are determined based on linear fitting of measured data using Debye and Arrhenius approaches. Conclusion/Recommendations: Two main relaxation processes were found ranging 2-10 and 10-20 $\mathrm{GHz}$, respectively. Dielectric dispersion is suggested to describe by combination of Cole-Davidson (CD) and Debye (Dy) processes. The results are discussed qualitatively based on bound states of water in hydrogel mixtures.
\end{abstract}

Key words: Dielectric constant, loss factor, PVA-water hydrogel, relaxation times

\section{INTRODUCTION}

Recently, the Polyvinyl Alcohol (PVA)-water hydrogel was used on medical application, such as healing agent, due to the composition of the hydrogel is very similar to the human body skin. In addition, there are non-toxic, non-carcinogenic and bioadhesive characteristics. Because of those properties, PVA is capable of simulating natural tissue and can be readily accepted by human body. In general, this medical application was interest for water content in the hydrogel is about $80 \%$ and the temperature is between $25-65^{\circ} \mathrm{C}$

In macroscopic observation, the mechanical characteristics, such as dielectric of polymer molecules are often considered. The dielectric properties can be used to explain the orientation of the molecules or relaxation mechanism in the polymer hydrogel (Sengwa and Kaur, 2000). However, the polarization molecules in polymers are complex due to many body interactions between binding molecules. Thus, a lot of the dielectric equation was modified from the ideal Debye theory, such as Cole-Cole (CC), Davidson-Cole (DC) and Havriliak-Negami (HN) as well as
Kohlrausch-Williams-Watts (KWW) distribution function, in order to represent and describe the properties of the polymer hydrogel.

In this study, a detailed macroscopic dielectric relaxation behavior of water in a PVA hydrogel was investigated and reported. The variable of environmental conditions considered are the water content, m.c, frequency, f under several temperature, $\mathrm{T}$ conditions. Then, the dielectric properties as a function of frequency and percentage water content in hydrogel were formulated. Finally, the bonding states of water molecules in hydrogel were discussed based on relaxation time, $\tau$ and mean activation energy, $Q$.

\section{MATERIALS AND METHODS}

Preparation of PVA-Water mixtures: Up to 11 different samples of Polyvinyl Alcohol (PVA), $\overline{\mathrm{M}} \mathrm{n}=72000$ weights $(1-15 \mathrm{~g})$ were mixed with $60 \mathrm{~g}$ of water in a small beaker, respectively. During the process of preparation sample, the water was heating indirectly between $65-90^{\circ} \mathrm{C}$ by mixing the PVA continuously little by little until dissolution is

Corresponding Author: You Kok Yeow, Department of Radio Communication Engineering,

Faculty of Electrical Engineering, University Technology Malaysia, 81310 UTM Skudai, Malaysia 
completed. After that, the mixture samples were kept at room temperature $(25 \pm 1)^{\circ} \mathrm{C}$. The percentage of water content in PVA-water mixture is calculated from the formula:

$\mathrm{m} . \mathrm{c}=\frac{\mathrm{m}_{\mathrm{Water}}}{\mathrm{m}_{\mathrm{PVA}}+\mathrm{m}_{\text {Water }}} \times 100 \%$

where, $\mathrm{m}_{\mathrm{PVA}}$ and $\mathrm{m}_{\text {Water }}$ are the weigh of PVA and water (in $\mathrm{g}$ ), respectively.

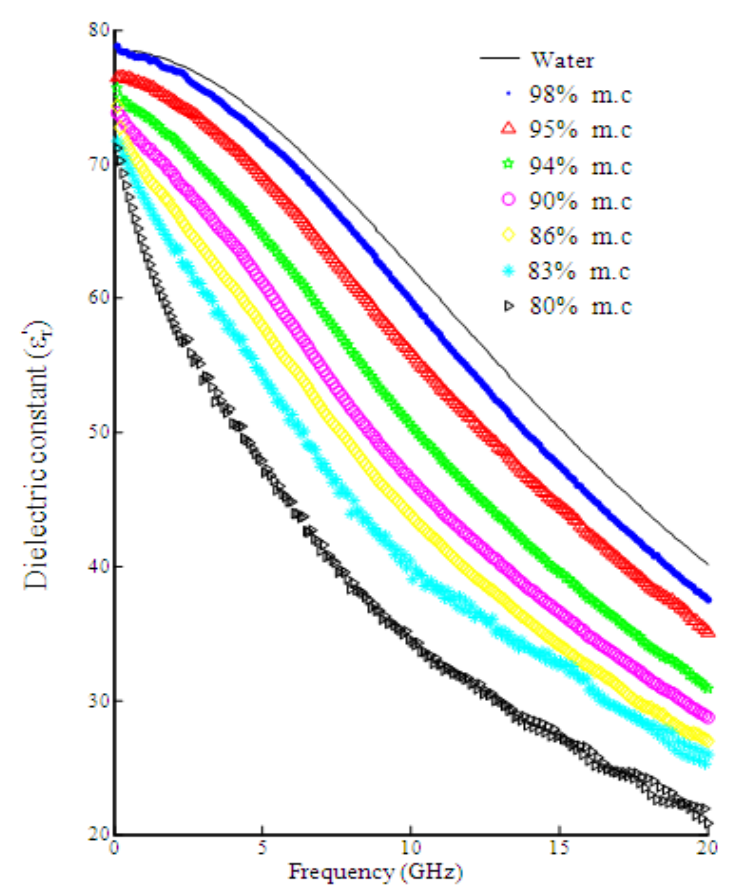

(a)
Dielectric measurements: The HP $85070 \mathrm{~B}$ openended coaxial sensor was used to determine the dielectric properties of PVA-water mixtures. The measurement apparatus consists of a computer controlled HP 8720B Vector Network Analyzer (VNA). In this study, air, metal short and deionized water were used as three dielectric references for calibration at aperture of open-ended coaxial sensor ranging $0.13-20 \mathrm{GHz}$ at $(25 \pm 1)^{\circ} \mathrm{C}$. After calibration, the sensor was immersed into the hydrogel sample to measure its relative permittivity.

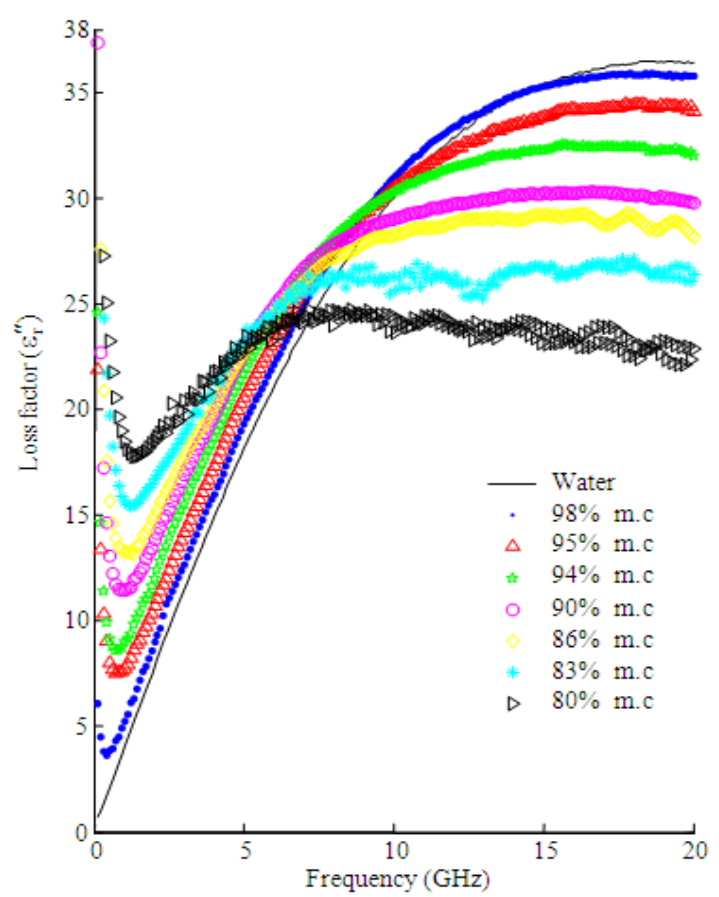

(b)

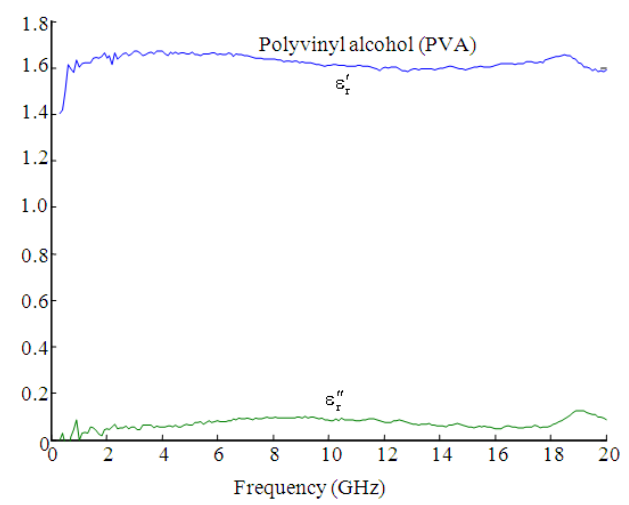

(c)

Fig. 1: Variation in measured of (a) dielectric constant, $\varepsilon_{\mathrm{r}}^{\prime}$; (b) loss factor, $\varepsilon_{\mathrm{r}}^{\prime \prime}$ with frequency at room temperature $(25 \pm 1)^{\circ} \mathrm{C}$ for various water content, m.c in PVA hydrogel; (c) The measured permittivity of Polyvinyl Alcohol (PVA) powder ranging $0.13-20 \mathrm{GHz}$ 
Am. J. Applied Sci., 7 (2): 270-276, 2010

\section{RESULTS AND DISCUSSION}

Analysis of data: In general, the relative permittivity of water $\left(\varepsilon_{\mathrm{r}}^{\prime} \approx 80\right)$ is far greater than PVA $\left(\varepsilon_{\mathrm{r}}^{\prime} \approx 1.6\right)$

(Fig. 1c), consequently, the dielectric properties of water content in PVA-water mixture is dominated. Figure $1 \mathrm{a}$ and $\mathrm{b}$ show the variation in dielectric constant, $\varepsilon_{\mathrm{r}}^{\prime}$ and loss factor, $\varepsilon_{\mathrm{r}}^{\prime \prime}$ of hydrogel with frequency at room temperature, $(25 \pm 1)^{\circ} \mathrm{C}$ for various percentage water content, m.c. In general, the curve of dielectric constant, $\varepsilon_{\mathrm{r}}^{\prime}$ of hydrogel mixtures is disperse broader and showed lower maxima of loss factor, $\varepsilon_{\mathrm{r}}^{\prime \prime}$ compared with pure water. The decrease in relative complex permittivity of the hydrogel mixture is caused by the displacement of polymer PVA molecules in water.

Dielectric modeling: The relative complex permittivity, $\varepsilon_{\mathrm{r}}$ of hydrogel may be calculated by using a sum of two relaxation processes, which is the combination of Cole-Davidson (CD) and Debye (Dy) processes. However, dispersion also exists at very low frequencies $(\leq 2 \mathrm{GHz})$ for dielectric constant, $\varepsilon_{\mathrm{r}}^{\prime}$ which has not been investigated in this study. Moreover, the loss factor, $\varepsilon_{\mathrm{r}}^{\prime \prime}$ at lowest frequencies $(\leq 3 \mathrm{GHz})$ is assumed entirely caused by conductivity, $\sigma$ and characterized as $\varepsilon_{\mathrm{r}}^{\prime \prime}=\sigma / 2 \pi \varepsilon_{0} \mathrm{f}$. Finally, the relative complex permittivity of hydrogel is expressed as:

$\varepsilon_{\mathrm{r}}=\varepsilon_{\infty}+\frac{\varepsilon_{\mathrm{s}}-\varepsilon_{1}}{\left[1+\left(\mathrm{j} \omega \mathrm{A}_{1} \tau_{1}\right)\right]^{\mathrm{A}_{2}}}+\frac{\varepsilon_{1}-\varepsilon_{\infty}}{1+\left(\mathrm{j} \omega \tau_{2}\right)}-\frac{\mathrm{j} \sigma}{2 \pi \varepsilon_{0} \mathrm{f}}$

where, $A_{1}$ and $A_{2}$ are the empirical constant, which are determined by optimized with measured data.

Finding relaxation time, $\tau$, static permittivity, $\varepsilon_{\mathrm{s}}$ and $\varepsilon_{1}$ : The static permittivity, $\varepsilon_{\mathrm{s}}$ and relaxation time, $\tau$ of hydrogel mixture can be predicted easily by linear Eq. 2 (Robert, 1988):

$\varepsilon_{\mathrm{r}}^{\prime}=-\left(\omega \varepsilon_{\mathrm{r}}^{\prime \prime}\right) \tau+\varepsilon_{\mathrm{s}}$

From (3), we observed that the gradient of variation in $\varepsilon_{\mathrm{r}}^{\prime}$ with $-\omega \varepsilon_{\mathrm{r}}^{\prime \prime}$ is represented by the relaxation time, $\tau$, as well as the point at $\varepsilon_{\mathrm{r}}^{\prime}$-axis, when $-\omega \varepsilon_{\mathrm{r}}^{\prime \prime}=0$ gives the value of $\varepsilon_{\mathrm{s}}$. The height of the intermediate plateau from the line in Fig. 2 represented as $\varepsilon_{1}$. The intersection between the line and $\varepsilon_{\mathrm{r}}^{\prime}$-axis gives the value of $\varepsilon_{\mathrm{s}}$. However, the Fig. 2 contains two linear slopes represented two major dispersions, which is broad low-frequency dispersion and high-frequency dispersion. The estimated values of dielectric constant $\left(\varepsilon_{\mathrm{s}}\right.$ and $\left.\varepsilon_{1}\right)$ and relaxation time $\left(\tau_{1}\right.$ and $\left.\tau_{2}\right)$ corresponding to various percentage of water content, m.c are revealed in Table 1.

Finding Optical Permittivity, $\varepsilon_{\infty}$ : In general, the optical permittivity, $\varepsilon_{\propto}$ is independent of frequency, $\mathrm{f}$ and temperature, T (Nyfors and Vainikainen, 1989). Thus, the $\varepsilon_{\propto}$ of hydrogel is assumed as mixture expression:

$\varepsilon_{\infty}=v_{\text {water }} \varepsilon_{\infty}^{\text {water }}+\left(1-v_{\text {water }}\right) \varepsilon_{\infty}^{\mathrm{PVA}}$

where, $\varepsilon_{\infty}^{\text {water }}=4.9$ and $\varepsilon_{\infty}^{\mathrm{PVA}}=1.6$ are the infinite optical permittivity of pure water, dry and dry PVA powder, respectively. The fraction volume of pure water, $v_{\text {water }}$ is calculated from:

$\mathrm{v}_{\text {water }}=\frac{\mathrm{m} \cdot \mathrm{c}\left(\rho_{\mathrm{PVA}}\right)}{100 \rho_{\text {water }}+\mathrm{m} \cdot \mathrm{c}\left(\rho_{\mathrm{PVA}}-\rho_{\text {water }}\right)}$
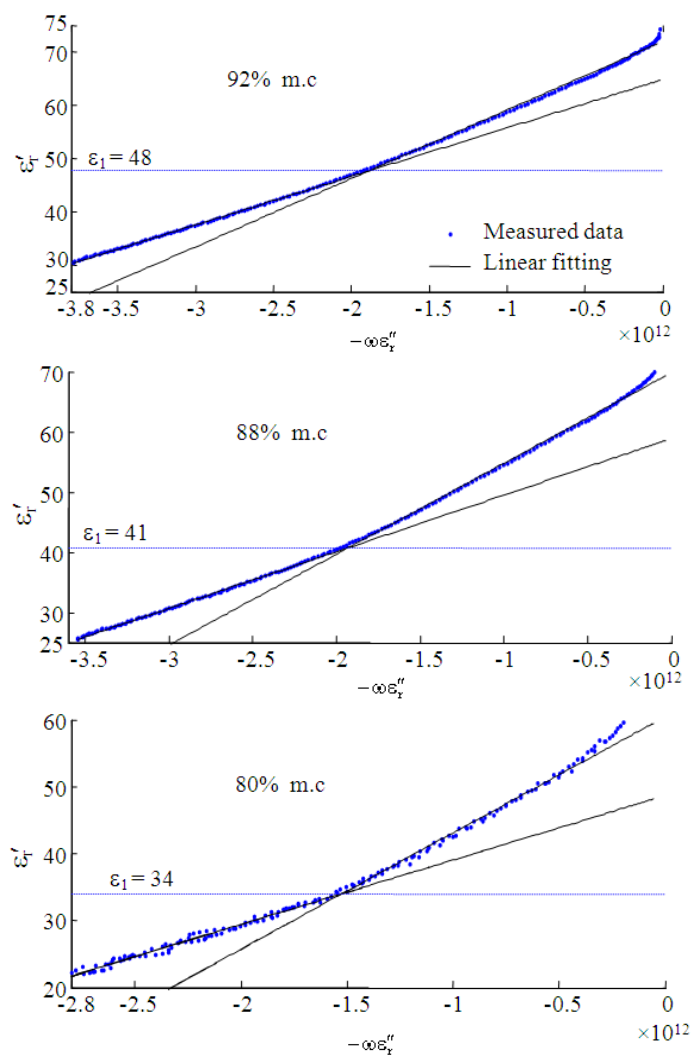

Fig. 2: The $\varepsilon_{\mathrm{r}}^{\prime}$ versus $-\omega \varepsilon_{\mathrm{r}}^{\prime \prime}$ for various water content, m.c, which plotting slope is represented the relaxation time, $\tau$ of PVA-water hydrogel at $(25 \pm 1)^{\circ} \mathrm{C}$ 
Am. J. Applied Sci., 7 (2): 270-276, 2010

Table 1: The estimated values of dielectric static $\left(\varepsilon_{\mathrm{s}}\right.$ and $\left.\varepsilon_{1}\right)$, relaxation time $\left(\tau_{1}\right.$ and $\left.\tau_{2}\right)$ and conductivity, $\sigma$ for various percentage of water content, m.c at room temperature based on fitting data in Fig. 2 and 3

\begin{tabular}{|c|c|c|c|c|c|c|c|}
\hline Water (g) & PVA (g) & m.c (\%) & $\sigma\left(\Omega^{-1} \mathrm{~m}^{-1}\right)$ & $\tau_{1}(\mathrm{ps})(1 \mathrm{st}$ fitting) & $\tau_{2}(\mathrm{ps})(2 \mathrm{nd}$ fitting) & $\varepsilon_{1}$ & $\overline{\varepsilon_{\mathrm{s}}}(1 \mathrm{st}$ fitting $)$ \\
\hline 60 & 1.0 & 98 & 0.04 & 11 & 8.9 & 73 & 78 \\
\hline 60 & 2.0 & 97 & 0.10 & 12 & 8.8 & 68 & 77 \\
\hline 60 & 3.0 & 95 & 0.15 & 12 & 8.5 & 55 & 76 \\
\hline 60 & 4.0 & 94 & 0.19 & 12 & 8.9 & 48 & 73 \\
\hline 60 & 5.0 & 92 & 0.20 & 13 & 9.1 & 48 & 72 \\
\hline 60 & 6.0 & 91 & 0.28 & 13 & 9.0 & 47 & 72 \\
\hline 60 & 7.0 & 90 & 0.30 & 14 & 9.0 & 45 & 71 \\
\hline 60 & 8.0 & 88 & 0.34 & 14 & 8.7 & 41 & 69 \\
\hline 60 & 10.0 & 86 & 0.41 & 14 & 9.0 & 39 & 68 \\
\hline 60 & 12.0 & 83 & 0.50 & 15 & 8.4 & 37 & 65 \\
\hline 60 & 15.0 & 80 & 0.60 & 18 & 9.0 & 34 & 61 \\
\hline
\end{tabular}

*: 1st fitting of measured data is from $2-10 \mathrm{GHz}$; 2nd fitting of measured data is from $10-20 \mathrm{GHz}$

Where:

$$
\begin{aligned}
\rho_{\text {water }}= & 0.9959 \mathrm{~g} \mathrm{~mL}^{-1} \\
\rho_{\mathrm{PVA}}= & 1.26 \mathrm{~g} \mathrm{~cm}^{-3} \text { are the apparent density of water } \\
& \text { and dry PVA powder at room temperature, } \\
& \text { respectively and m.c is the percentage of water } \\
& \text { content in the PVA hydrogel }
\end{aligned}
$$

Finding conductivity, $\sigma$ : The conductivity term, $\sigma$ is determined by optimizing with measured loss factor, $\varepsilon_{\mathrm{r}}^{\prime \prime}$ at low frequency $(\leq 5 \mathrm{GHz})$ with (1). The estimated values of conductivity, $\sigma$ are listed in Table 1 , as well as plotted as Fig. 3. The conductivity data increases in linear form with water content, m.c in the mixtures as revealed in Fig. 3. However, the apparent conductivity itself is independent of frequency. The linear scope may be calibrated directly in percent of water content, m.c. The obtained fitted parameters as a function of water content, m.c (\%) for (1) are listed in Table 2.

Macroscopic analysis: The measurement results by using HP coaxial sensor and calculated values of (1) can be compared between Fig. 1a and $\mathrm{b}$ and 4 . Clearly, the calculated values in Fig. 4 are quite consistent with measured data in Fig. 1a and b. The values of relaxation time, $\tau$ obtained from Fig. 4 are available in Table 1 . The relaxation time, $\tau$ is higher at low frequencies (below $10 \mathrm{GHz}$ ) and decrease with water content m.c, in hydrogel due to the orientation polarization of polar molecules is slowed down by the binding of water molecules and PVA in the mixtures. The water molecules are directly attached by swelling into the groups of polymer molecule in the main chain and replaces cross-links between PVA molecules. It is a main factor to limit its movement and relaxation time, $\tau$ increase compare with free water molecules. In addition, the water molecules can also be hydrogen bonded with hydrophilic groups ($\mathrm{OH})$ in the side chain of the PVA molecule. This type of bond is caused by predominantly Coulombic forces and has little effect on the rigidity of the structure.

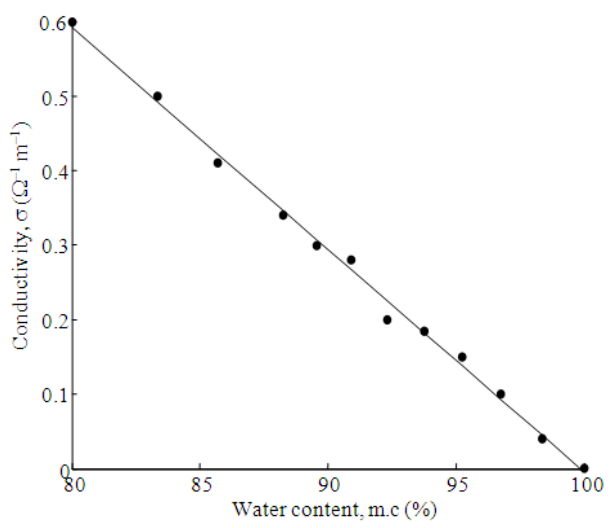

Fig. 3: Variation in conductivity, $\sigma$ with percentage of water content, m.c in PVA-water hydrogel with linear fit

Table 2: The relationship between each of parameters in Eq. 1 with water content, m.c (\%)

Dielectric parameters of PVA-water hydrogel in Eq. 1 $(80 \% \leq \mathrm{m} . \mathrm{c} \leq 98.5 \% ; 100 \%) ;(0.13 \mathrm{GHz} \leq \mathrm{f} \leq 20 \mathrm{GHz}) ; 25^{\circ} \mathrm{C}$

$\varepsilon_{\mathrm{s}}=1.18833 \times 10^{3}$ (m.c) $)^{3}-0.330562(\mathrm{~m} . \mathrm{c})^{2}+31.4052$ (m.c) +944.058

$\varepsilon_{1}=-9.15419 \times 10^{-4}(\mathrm{~m} . \mathrm{c})^{4}+0.341051(\mathrm{~m} . \mathrm{c})^{3}-47.3823(\mathrm{~m} . \mathrm{c})^{2}$

$+2.91189 \times 10^{3}$ (m.c) $-6.67939 \times 10^{4}$

$\varepsilon_{\infty}=v_{\text {water }} \varepsilon_{\infty}^{\text {water }}+\left(1-v_{\text {water }}\right) \varepsilon_{\infty}^{\text {PVA }}$

where: $\varepsilon_{\infty}^{\text {water }}=4.9 \quad \varepsilon_{\infty}^{\mathrm{PVA}}=1.6$

$\tau_{1}=-2.52953 \times 10^{-15}(\mathrm{~m} . \mathrm{c})^{3}+6.8418 \times 10^{-13}(\mathrm{~m} . \mathrm{c})^{2}-6.18714 \times 10^{-11}$

(m.c) $+1.88378 \times 10^{-9} \mathrm{~s}$

$\tau_{2}=8.5 \times 10^{-14} \mathrm{~s} ; \quad \sigma=-2.96099 \times 10^{-2}(\mathrm{~m} . \mathrm{c})+2.95783 \quad \Omega^{-1} \mathrm{~m}^{-1}$

$\mathrm{A}_{1}=5.61583 \times 10^{-4}$ (m.c) ${ }^{2}+0.0893697$ (m.c) +4.311717

$\mathrm{A}_{2}=0.0535328(\mathrm{~m} . \mathrm{c})+6.687$

However, the relaxation time of hydrogel is approximately equal to the relaxation of free water (8.4 ps) for frequencies above $10 \mathrm{GHz}$. Obviously, energy above $10 \mathrm{GHz}$ is large enough to break the hydrogen bond between water molecules and hydrophilic groups of PVA. In fact, the overall effect on water structure is extremely complex. 


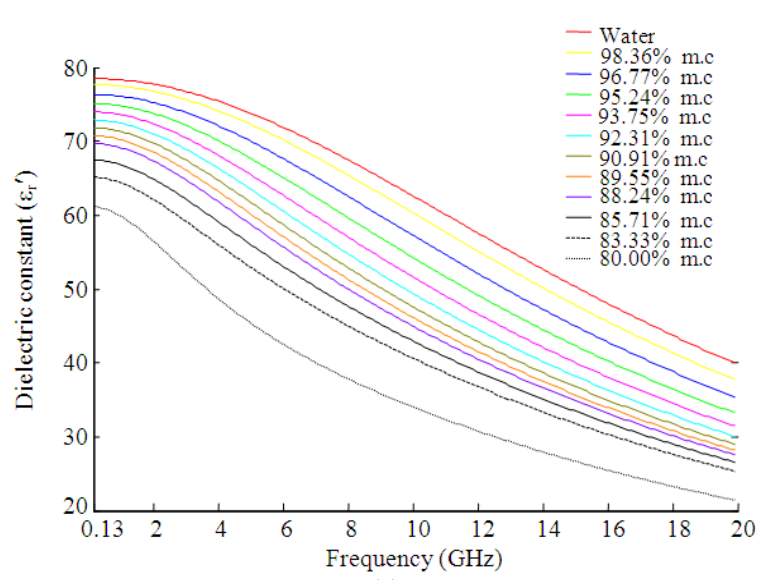

(a)

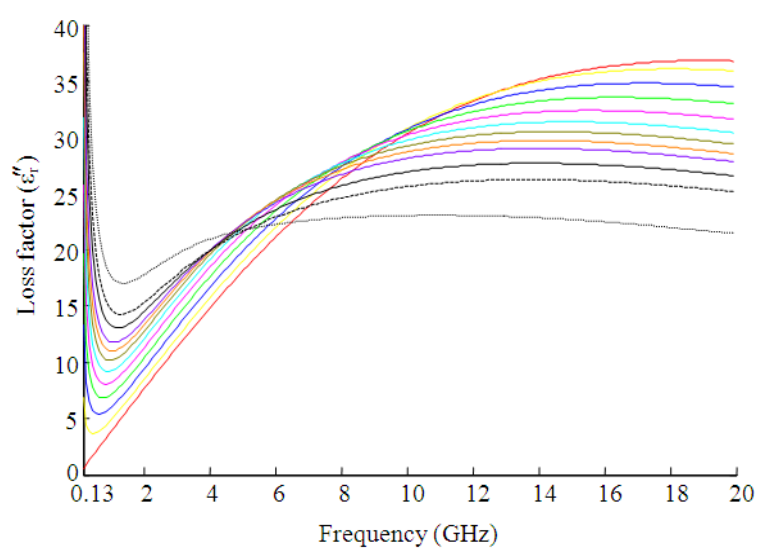

(b)

Fig. 4: Variation in calculated of dielectric constant, $\varepsilon_{\mathrm{r}}^{\prime}$ and loss factor, $\varepsilon_{\mathrm{r}}^{\prime \prime}$ with frequency at room temperature $(25 \pm 1)^{\circ} \mathrm{C}$ for various water content, m.c in PVA hydrogel

Temperature effects analysis: Figure 5 shows the $\varepsilon_{\mathrm{r}}^{\prime}$ versus $-\omega \varepsilon_{\mathrm{r}}^{\prime \prime}$ plot for pure water at various temperature, T. The measured relaxation time, $\tau$ of bulk water ranging $25-60^{\circ} \mathrm{C}$ can be obtained from fitting of Fig. 5 by using (2) are tabulated in Table 3 . It is expected that the hydrogen bonds are broken at high temperature, which leads to increase in mobility of side chains or decreases of the relaxation time, $\tau$. The relaxation time, $\tau$ of water and PVA hydrogel are plotted as Arrhenius (Hasted, 1973) plots in Fig. 6. The linear relationships in Fig. 6 indicate that the temperature dependence of the relaxation time can be described by (6):

$$
\ln (\tau)=\mathrm{Q}\left(\frac{1}{\mathrm{R}(\mathrm{T}+273)}\right)+\ln \left(\tau_{\mathrm{o}}\right)
$$

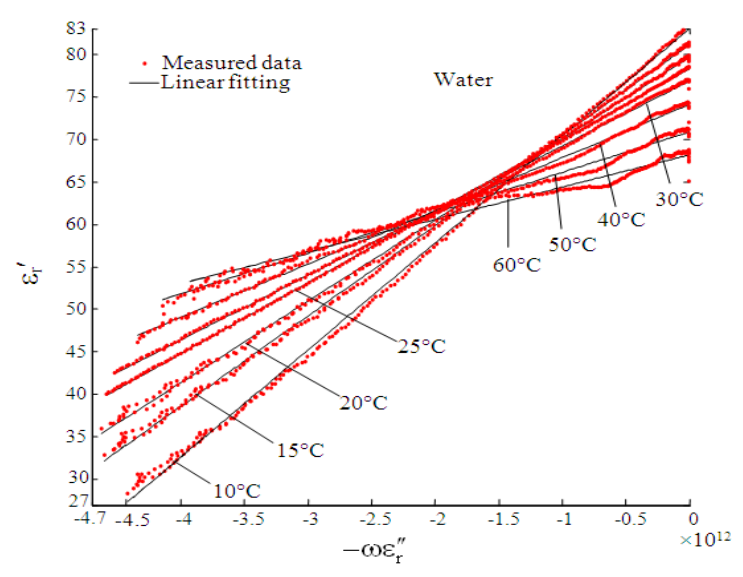

Fig. 5: The measured $\varepsilon_{\mathrm{r}}^{\prime}$ versus $-\omega \varepsilon_{\mathrm{r}}^{\prime \prime}$, which plotting slope is represented the relaxation time, $\tau$ of water at 10 , $15,20,25,30,40,50$ and $60^{\circ} \mathrm{C}$

Table 3: The estimated values of relaxation time, $\tau$ for pure water and PVA hydrogel under several temperature, $T$

\begin{tabular}{|c|c|c|c|c|}
\hline Sample & $\mathrm{T}\left({ }^{\circ} \mathrm{C}\right)$ & $\begin{array}{l}\tau(\mathrm{ps}) \\
\text { This study }\end{array}$ & $\begin{array}{l}\text { Kaatze, } \\
(2005)\end{array}$ & $\begin{array}{l}\text { Hasted, } \\
\text { (1973) }\end{array}$ \\
\hline \multirow[t]{8}{*}{ Water } & 10 & 13.0 & 12.68 & 12.60 \\
\hline & 15 & 11.0 & 10.84 & - \\
\hline & 20 & 9.6 & 9.37 & 9.30 \\
\hline & 25 & 8.4 & 8.28 & - \\
\hline & 30 & 7.6 & 7.31 & 7.20 \\
\hline & 40 & 6.3 & 5.82 & 5.80 \\
\hline & 50 & 4.8 & 4.75 & 4.80 \\
\hline & 60 & 3.8 & 4.01 & 3.90 \\
\hline \multirow{8}{*}{$\begin{array}{l}97 \% \text { m.c } \\
\text { Hydrogel }\end{array}$} & & & \multicolumn{2}{|l|}{ This study } \\
\hline & & & $2-10 \mathrm{GHz}$ & $10-20 \mathrm{GHz}$ \\
\hline & 25 & & 12.0 & 8.80 \\
\hline & 30 & & 9.5 & 8.00 \\
\hline & 35 & & 8.9 & 7.40 \\
\hline & 40 & & 8.0 & 6.30 \\
\hline & 45 & & 7.9 & 6.10 \\
\hline & 50 & & 7.9 & 5.80 \\
\hline \multirow{8}{*}{$\begin{array}{l}83 \% \text { m.c } \\
\text { hydrogel }\end{array}$} & & & \multicolumn{2}{|l|}{ This study } \\
\hline & & & $2-10 \mathrm{GHz}$ & $10-20 \mathrm{GHz}$ \\
\hline & 25 & & 16.0 & 8.30 \\
\hline & 30 & & 15.0 & 8.00 \\
\hline & 35 & & 14.0 & 7.40 \\
\hline & 40 & & 13.0 & 6.60 \\
\hline & 45 & & 13.0 & 6.40 \\
\hline & 50 & & 13.0 & 6.20 \\
\hline \multirow{8}{*}{$\begin{array}{l}80 \% \text { m.c } \\
\text { hydrogel }\end{array}$} & & & \multicolumn{2}{|l|}{ This study } \\
\hline & & & $2-10 \mathrm{GHz}$ & $10-20 \mathrm{GHz}$ \\
\hline & 25 & & 18.0 & 9.70 \\
\hline & 30 & & 17.0 & 8.90 \\
\hline & 35 & & 15.0 & 8.30 \\
\hline & 40 & & 15.0 & 7.90 \\
\hline & 45 & & 14.0 & 7.50 \\
\hline & 50 & & 14.0 & 7.50 \\
\hline
\end{tabular}

Where:

$\tau_{\mathrm{o}}=\frac{\mathrm{h}}{\mathrm{k}(\mathrm{T}+273)} \exp (-\Delta \mathrm{S} / \mathrm{R})$ 
Where:

$\mathrm{R}=$ the gas constant $\left(\mathrm{R}=8.3143 \mathrm{~J} \mathrm{~mol}^{-1} \mathrm{~K}^{-1}\right)$

$\mathrm{k}=$ The Boltzman constant $\left(\mathrm{k}=1.38066 \times 10^{-23} \mathrm{~J} \mathrm{~K}^{-1}\right)$

$\mathrm{h}=$ The Phanck constant $\left(\mathrm{h}=6.62608 \times 10^{-34} \mathrm{~J} \mathrm{sec}^{-1}\right)$

The linear slope in Fig. 6 represents the mean activation energy, $\mathrm{Q}$ of bulk water and gives $18.3 \mathrm{~kJ} \mathrm{~mol}^{-1}$ compare with literature (Nyfors and Vainikainen, 1989) value $18.8 \mathrm{~kJ} \mathrm{~mol}^{-1}$. While, the estimated value of $\operatorname{In}\left(\tau_{\mathrm{o}}\right)$ is -32.877 or $\tau_{\mathrm{o}}=5.27 \times 10^{-15}$ sec. Indirectly, the entropy change, $\Delta S$ can be determined from $\tau_{0}$. The similar procedures are implemented in PVA hydrogel and the mean activation energy, Q for 96.8 and $80.0 \%$ m.c hydrogel are estimated between 12.1 and $5.45 \mathrm{~kJ} \mathrm{~mol}^{-1}$ for $2-10$ $\mathrm{GHz}$ and 14.2 and $5.84 \mathrm{~kJ} \mathrm{~mol}^{-1}$ for $10-20 \mathrm{GHz}$, respectively, as listed in Table 4. This mean that the energy, Q released (or absorbed) per mole for the hydrogen bond are formed in PVA hydrogel, are less than the hydrogen bonds formed in pure water for entire frequency. In other word, the lower value of Q, the more stable of the hydrogel. In additional, a negative value of $\Delta \mathrm{S}$ indicates a decrease in entropy, the less random in saturated hydrogel system.

Figure 7 shows the variation in relative permittivity, $\varepsilon_{\mathrm{r}}$ of PVA hydrogel with frequency for various temperature, T. As mention earlier, the binding between PVA chain and water molecules are very stable for high concentrated hydrogel, thus the slight higher temperature or energy is not significant to polarize the molecules in the hydrogel compared to the pure water.

Table 4: The estimated values of mean activation energy, $\mathrm{Q}$ and relaxation coefficient, $\tau_{0}$ for pure water and PVA hydrogel for frequency range of $2-20 \mathrm{GHz}$

\begin{tabular}{|c|c|c|c|c|c|c|}
\hline Sample & $\begin{array}{c}\mathrm{f} \\
(\mathrm{GHz})\end{array}$ & $\begin{array}{c}\mathrm{Q} \\
\left(\mathrm{kJ} \mathrm{mol}^{-1}\right)\end{array}$ & $\ln \left(\tau_{\mathrm{o}}\right)$ & $(\mathrm{ps})\left(\tau_{\mathrm{o}}\right)$ & $\begin{array}{l}\mathrm{T} \\
\left({ }^{\circ} \mathrm{C}\right)\end{array}$ & $\begin{array}{l}\Delta \mathrm{S} \\
\left(\mathrm{J}(\mathrm{K} \mathrm{mol})^{-1}\right)\end{array}$ \\
\hline \multirow[t]{3}{*}{ Water } & \multirow[t]{3}{*}{$2-20$} & \multirow[t]{3}{*}{18.0} & \multirow[t]{3}{*}{-33} & \multirow[t]{3}{*}{0.0053} & 25 & 28.0 \\
\hline & & & & & 40 & 28.0 \\
\hline & & & & & 60 & 28.0 \\
\hline \multirow{6}{*}{$\begin{array}{l}97 \% \text { m.c } \\
\text { hydrogel }\end{array}$} & \multirow[t]{3}{*}{$2-10$} & \multirow[t]{3}{*}{12.0} & \multirow[t]{3}{*}{-30} & \multirow[t]{3}{*}{0.0810} & 25 & 5.7 \\
\hline & & & & & 40 & 5.3 \\
\hline & & & & & 60 & 4.8 \\
\hline & \multirow[t]{3}{*}{$10-20$} & \multirow[t]{3}{*}{14.0} & \multirow[t]{3}{*}{-31} & \multirow[t]{3}{*}{0.0280} & 25 & 14.0 \\
\hline & & & & & 40 & 14.0 \\
\hline & & & & & 60 & 14.0 \\
\hline \multirow{6}{*}{$\begin{array}{l}83 \% \text { m.c } \\
\text { hydrogel }\end{array}$} & \multirow[t]{3}{*}{$2-10$} & \multirow[t]{3}{*}{5.1} & \multirow[t]{3}{*}{-27} & \multirow[t]{3}{*}{0.020} & 25 & -21.0 \\
\hline & & & & & 40 & -21.0 \\
\hline & & & & & 60 & -22.0 \\
\hline & \multirow{3}{*}{$10-20$} & \multirow[t]{3}{*}{7.0} & \multirow[t]{3}{*}{-28} & \multirow[t]{3}{*}{0.4900} & 25 & -9.3 \\
\hline & & & & & 40 & -9.7 \\
\hline & & & & & 60 & -10.0 \\
\hline \multirow{6}{*}{$\begin{array}{l}80 \% \text { m.c } \\
\text { hydrogel }\end{array}$} & \multirow[t]{3}{*}{$2-10$} & \multirow[t]{3}{*}{5.5} & \multirow[t]{3}{*}{-27} & \multirow[t]{3}{*}{2.0000} & 25 & -21.0 \\
\hline & & & & & 40 & -21.0 \\
\hline & & & & & 60 & -22.0 \\
\hline & \multirow[t]{3}{*}{$10-20$} & \multirow[t]{3}{*}{5.8} & \multirow[t]{3}{*}{-28} & \multirow[t]{3}{*}{0.9000} & 25 & -14.0 \\
\hline & & & & & 40 & -15.0 \\
\hline & & & & & 60 & -15.0 \\
\hline
\end{tabular}

This condition will cause the relative permittivity, $\varepsilon_{\mathrm{r}}$ of PVA hydrogel are evident less sensitive to higher temperature $\left(>30^{\circ} \mathrm{C}\right)$, especially for PVA hydrogel with low water content $(<80 \%$ m.c $)$ as shown in Fig. 7 .

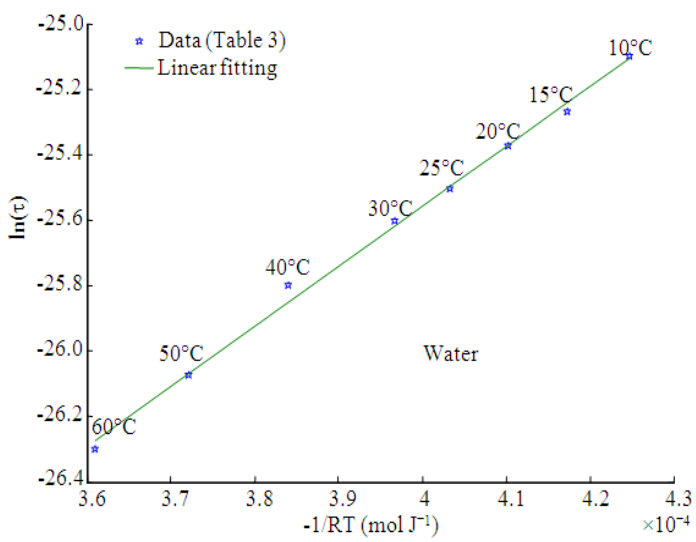

(a)

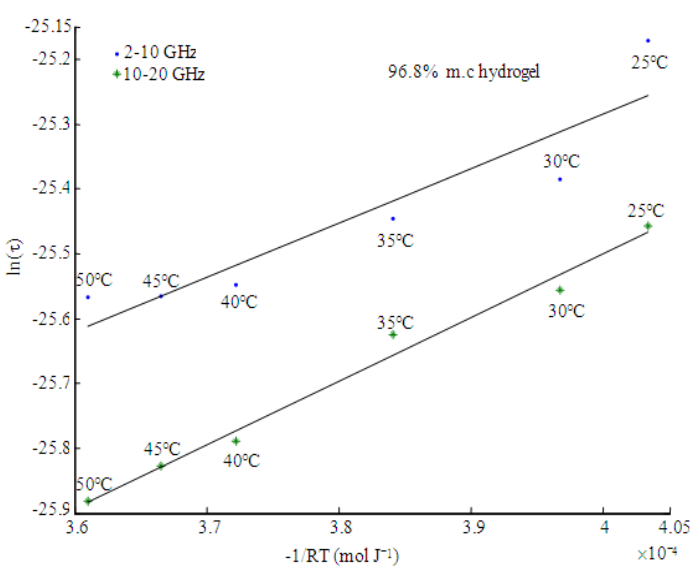

(b)

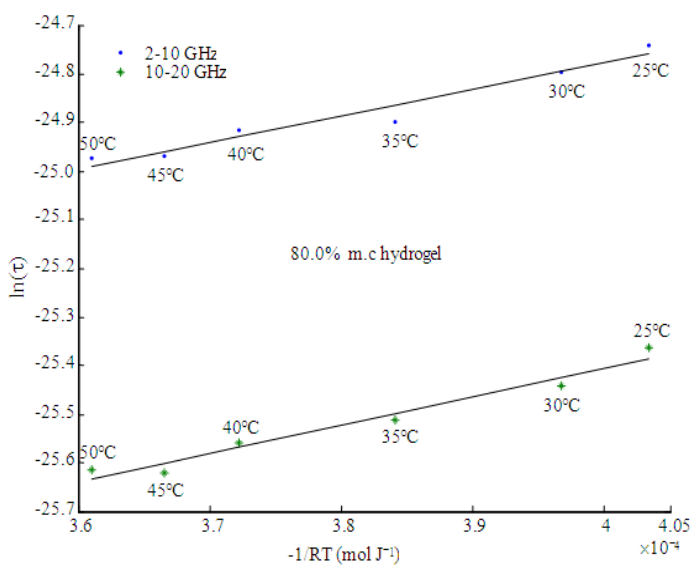

(c)

Fig. 6: Arrhenius plots for bulk water and PVA hydrogel 


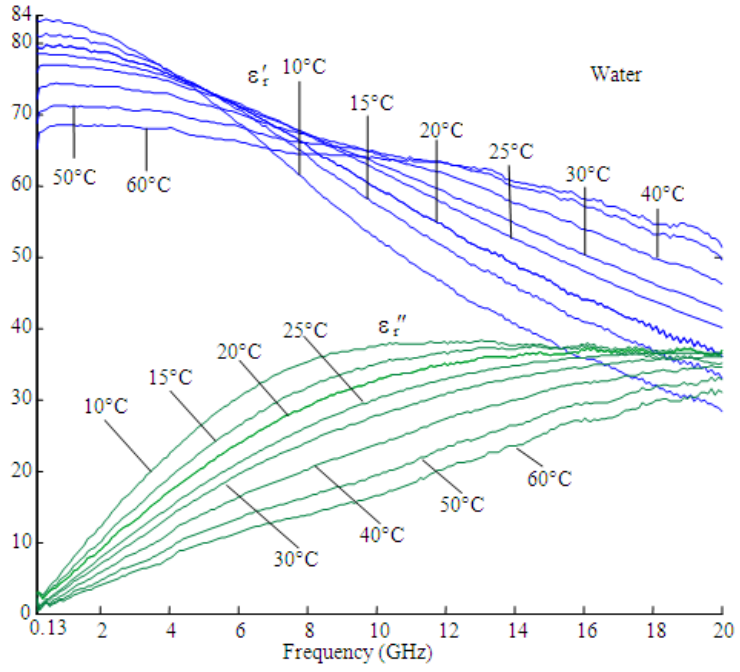

(a)

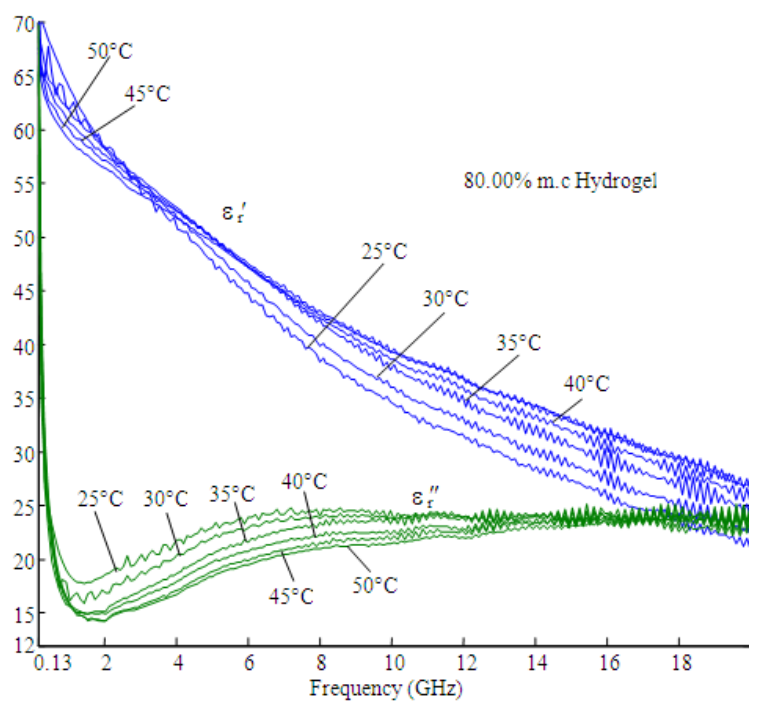

(b)

Fig. 7: Variation in relative permittivity, $\varepsilon_{\mathrm{r}}$ of (a) water and (b) $80 \%$ m.c PVA hydrogel with frequency for various temperature, $\mathrm{T}$

\section{CONCLUSION}

In this study, a linear fitting method was used to replace complicated numerical routine for finding out the calculating dielectric parameters. The linear polynomial fitting is used to estimate the values of dielectric static, $\varepsilon_{\mathrm{s}}$ relaxation time, $\tau$ and mean activation energy, $\mathrm{Q}$ as well as entropy change, $\Delta \mathrm{S}$. The rigorous dielectric model which is consists of two relaxation processes, is created successfully to describe the electric properties of the PVA hydrogel mixture.

\section{REFERENCES}

Hasted, J., 1973. Aqueous Dielectrics. Chapman and Hall, New York, ISBN: 412098008, pp: 302.

Kaatze, U., 2005. Electromagnetic Wave Interactions with Water and Aqueous Solutions. In: Electromagnetic Aquametry, Kupfer, K. (Ed.). Springer, New York, ISBN: 3540222227, pp: 15-37.

Nyfors, E. and P. Vainikainen, 1989. Industrial Microwave Sensors. Artech House, Norwood, MA., ISBN: 0890063974, pp: 351.

Robert, P., 1988. Electric and Magnetic Properties of Materials. Artech House, Norwood, MA., ISBN: 0890062625, pp: 458.

Sengwa, R.J. and K. Kaur, 2000. Dielectric Dispersion studies of poly(vinyl alcohol) in aqueous solutions. Polymer Int., 49: 1314-1320. DOI: 10.1002/10970126(200011)49: 11<1314::AID-PI479>3.0.CO;2-8 